This is the pre-peer reviewed version of the following article:

\title{
Place fields and the cognitive map
}

Paul A. Dudchenko ${ }^{1,2}$ and Emma R. Wood ${ }^{2}$

\begin{abstract}
which has been published at: http://onlinelibrary.wiley.com/doi/10.1002/hipo.22450/full This article may be used for non.commercial purposes in accordance with Wiley Terms and Conditions for Self Archiving.
\end{abstract}

Hippocampus 25: 709-712 (2015)

${ }^{1}$ University of Stirling

Psychology, School of Natural Sciences

Stirling, FK9 4LA

United Kingdom

Phone: +441316503531

${ }^{2}$ University of Edinburgh

Centre for Cognitive and Neural Systems

School of Biomedical Sciences

1 George Square

Edinburgh, EH8 9JZ

United Kingdom

Corresponding authors: p.a.dudchenko@stir.ac.uk; emma.wood@ed.ac.uk

Manuscript: 14 pages, 2 figures

Running title: Cognitive maps

Key words: Place cells, Tolman, spatial cognition

Acknowledgements: The authors would like to thank Roddy Grieves for sharing his preliminary data. 
Abstract

The discovery of place cells by John O'Keefe in the early 1970s was a breakthrough not just for systems neuroscience, but also for psychology: place fields provided a clear neural substrate for the notion of a cognitive map, a construct devised to explain rat learning and spatial cognition. However, is the robust locationrelated firing of place cells still best conceptualised as a cognitive map? In this article, we wish to reassess this view of hippocampus function in light of subsequent findings on place cells. 


\section{Cognitive maps in rats and humans}

In the early decades of the $20^{\text {th }}$ century, experimenters in psychology began to study the mental processes of animals, both to better understand their capacities (Hunter, 1913), and to study basic learning and memory questions under more controlled conditions (Watson, 1907). The latter led to a simple, yet powerful account of behaviour: certain stimuli $(S)$ were associated with specific response $(R)$, and linkages between the two could account for how an animal solved a maze (Hull, 1943). Though useful, in the 1930s and 1940s, Tolman and his students conducted a series of experiments which challenged this account. For them, a series of S-R associations was not sufficient to capture the range of behaviors observed. Rather, rats, the subjects of their studies, were found to sample their environments prior to making responses (i.e., vicarious trial-and-error behaviors), to display learning in the absence of reward, and to develop an overall representation of a labyrinth based on partial experience. Tolman argued that a flexible cognitive map provided a better account for behaviour (Tolman, 1948).

\section{Place cells and the cognitive map}

The debate between S-R and representational accounts of behavior continued, and a resolution was that rats would use a place strategy (that is, learn the allocentric location of a reward) under certain training conditions, and a response strategy (e.g., always turn left) under others (Restle, 1957). There, perhaps, the story might have rested were it not for the discovery of place cells by John O'Keefe. 
In the first paper on place cells the link between place cells and cognitive mapping was explicit:

These findings suggest that the hippocampus provides the rest of the brain with a spatial reference map. (pg. 174, O'Keefe and Speakman, 1971)

This map, the authors note, may not just reflect the instantaneous position of the animal, but might also be coupled with a signal that indicated potential movement, such that future spatial positions might be represented. But the central, and very reasonable assumption, is that the hippocampus represents locations in an allocentric, map-like way:

The end point of the chapter will be the assertion that the hippocampus acts as a cognitive mapping system, which we shall call the locale system and which generates place hypotheses and exploration. (pg. 89-90, O'Keefe \& Nadel, 1978.)

For O'Keefe and Nadel, the representation of space provided by the hippocampus was an instantiation of a flexible place map, in the Tolmanian sense. This is in contrast with a non-hippocampal, taxon representation that is akin to earlier stimulus-response notions.

Of course, the discovery of other remarkable representations of space in the brain was to follow: head direction cells (Ranck Jr, 1985; Taube et al., 1990), grid 
cells (Hafting et al., 2005), and border cells (Lever et al., 2009, Solstad et al., 2009). In general, these have not been as explicitly linked to the notion of a cognitive map, though as likely inputs to the map (Zhang et al., 2013), they appear to provide more unambiguous allocentric information compared to place cells, as discussed below.

\section{Place cells: local vs. global maps}

Since O'Keefe's discovery, additional features of place cells have been identified. In many ways, place cells behave as they ought in a spatial sense: their fields are anchored to salient landmarks in the environment (Muller \& Kubie, 1987), they remap in different environments (Kubie \& Ranck, 1983), they are linked to the theta rhythm (O'Keefe \& Recce, 1993), and they respond to new features of the environment (O’Keefe, 1976; Hollup et al., 2001).

But a feature of place fields that has recently become apparent argues against the place cell representation as a global map of space. This feature is the control of place fields by local boundaries. Some of the first evidence for this was provided by O'Keefe and Burgess (1996) with their finding that place fields appeared to be anchored to the walls in a square or a rectangular environment. If the walls were stretched, the place fields became elongated. This could be accounted for with a model where place fields were the sum of tuning curves reflecting the distance from each wall. Additional evidence was provided by Skaggs and McNaughton (1998), who showed that a subset of place cells fired in the same relative location in two connected, and visually identical, rooms. Moreover, if a boundary is added into 
an environment parallel to an existing wall, an active place cell will exhibit an additional field (Barry et al., 2006).

This property of place cells - a reliance on local boundaries - is predicted by the boundary vector model of place cells from Neil Burgess and colleagues (Hartley et al., 2000). An implication of this view is that if multiple boundaries parallel to one another are present, multiple fields will be observed. Empirical results confirm this. Derdikman et al. (2009) observed repetition of place fields in equivalent locations in the different arms of a hairpin maze, and a similar repetition - which the authors referred to as fragmentation - in grid cells. Most strikingly, Spiers et al. (2013) showed stable and consistent repetition of place fields in four adjacent parallel chambers that were visually and geometrically the same as each other. We have observed similar results (Figure 1), and have found that rats have difficulty discriminating adjacent, parallel compartments at a behavioural level (Grieves et al., 2014).

As Spiers et al. (2013) have argued, this repetition of place fields suggests that the place cell map is local, not global. It also indicates that place cells are driven primarily by sensory information from the environment (including distance and direction from local boundaries and landmarks, and contextual cues (such as colour and odour) that may define a local region of the environment), and that they do not use path integration to disambiguate the different subregions of an extended environment. 
But is a local representation best conceived of as a map? We would argue that it is not. A map allows the spatial relationship between locations that cannot be directly perceived to be known. Place cells, driven by local cues, don't quite do this. Rather, they behave as a location recognition system. This is a subtle, but important distinction. As Whishaw and colleagues (1995) argued, following damage to the fimbria, a distinction can be made between getting there and knowing where. A map is essential for the first, a pattern matching device is necessary for the second. Place cells may thus inform the animal where it is relative to the boundaries of a given environment. Different environments can be distinguished based on contextual cues, landmarks, and shapes. However, similar environments yield similar place cell representations and, presumably, are difficult to tell apart.

\section{Place cells: trajectory encoding}

A second feature of place cell firing that makes their activity less-than-ideal for representing global space is their modulation by ongoing behaviour. In a well-trained maze task where an animal repeatedly traverses the same location on its way to or from different goals, place cell firing is strongly modulated by the specific origin and destination of the animal's route (Figure 2; Wood et al., 2000; Frank et al., 2000; Ferbinteanu \& Shapiro, 2003; Bower et al., 2005; Shapiro et al., 2006 Ainge et al., 2007; Ji \& Wilson, 2008; Catanese et al. 2014).

This modulation of place fields by behaviour is consistent with a representation of the animal's ongoing behaviour in a specific location, but less so 
with a literal representation of space. Rather, it suggests that on overlapping routes, place fields represent progress along a trajectory (see also Pastalkova et al., 2008; McDonald et al., 2011). In this way the place cell representation may be more cognitive than map-like.

Interestingly, this modulation of place cell activity by ongoing behaviour does not appear to occur automatically, simply as a result of the animal traversing the same location on different routes. Specifically, it is not observed in animals running the same routes in the same testing environments under conditions when all possible goals are rewarded, and so the choice of goal and route is presumably less important (Smith and Mizumori, 2006; Hosburn et al, 2008). Rather, it develops as animals start using a goal-directed strategy for solving the ongoing spatial task. This suggests that the hippocampal representation is dynamic rather than being a static representation of location.

\section{Summary}

The remarkable discovery of place cells by John O'Keefe suggested that location-specific representations might form a map of allocentric space. However, subsequent findings indicate that place cells do not appear to provide a static representation of global space. Rather, place cells appear to encode the environment, including the animal's experience, in a more dynamic, and a more local manner. They are dynamic, in the sense that they show encoding of not just location, but of trajectory and sequence, in an experience-dependent fashion. They 
are local, in the sense that they are driven by local boundaries and cues, and if these are repeated - even in adjacent compartments - the map repeats. As a means of localisation in global space, place cells may only incidentally provide a map. What they may provide instead is a mechanism for associating specific locations with behaviours and events that occur there. 


\section{References}

Bower MR, Euston DR, McNaughton BL. 2005. Sequential-context-dependent hippocampal activity is not necessary to learn sequences with repeated elements. The Journal of Neuroscience 25: 1313-1323.

Catanese J, Viggiano A, Cerasti E, Zugaro MB, Wiener SI. 2014. Retrospectively and prospectively modulated hippocampal place responses are differentially distributed along a common path in a continuous T-maze. The Journal of Neuroscience 34: 13163-13169.

Ferbinteanu J, Shapiro ML. 2003. Prospective and retrospective memory coding in the hippocampus. Neuron 40: 1227-1239.

Frank LM, Brown EN and Wilson MA. 2000. Trajectory encoding in the hippocampus and entorhinal cortex. Neuron 27: 169-178.

Grieves RM, Jenkins BW, Wood ER, Dudchenko PA. 2014. Does place field repetition impair spatial learning? Society for Neuroscience Abstracts, 264.13.

Hafting T, Fyhn M, Molden S, Moser M-B, Moser El. 2005. Microstructure of a spatial map in the entorhinal cortex. Nature 436: 801-806.

Hartley T, Burgess N, Lever C, Cacucci F, O’Keefe J. 2000. Modeling place fields in terms of the cortical inputs to the hippocampus. Hippocampus 10: 369-379.

Hollup SA, Molden S, Donnett JG, Moser M-B, Moser El. 2001. Accumulation of 
hippocampal place fields at the goal location in an annular watermaze task. The Journal of Neuroscience 21: 1635-1644.

Hosburn CH, Huang SYC, Dudchenko PA, Wood ER. (2008). The development of prospective goal-dependent firing in hippocampal place cells, and its relationship to behaviour. FENS Abstracts 4: 128.13.

Hunter WS. 1913. Studies from the psychological laboratory of the University of Chicago: The delayed reaction in animals and children. Behavior monographs: Serial number 6. Vol 2(1) New York, NY, US: Henry Holt and Co.

Ji D, Wilson MA. 2008. Firing rate dynamics in the hippocampus induced by trajectory learning. The Journal of Neuroscience 28: 4679-4689.

Kubie JL, Ranck JBJr. 1983. Sensory-behavioral correlates in individual hippocampus neurons in three situations: space and context. In: Seifert W, editor. Neurobiology of the Hippocampus. New York: Academic Press. p 433447.

Lever C, Burton S, Jeewajee A, O'Keefe J, Burgess N. 2009. Boundary vector cells in the subiculum of the hippocampal formation The Journal of Neuroscience 29: 9771-9777.

MacDonald CJ, Lepage KQ, Eden UT, Eichenbaum H. 2011. Hippocampal "time 
cells" bridge the gap in memory for discontiguous events. Neuron 7: 737-749.

Muller RU and Kubie JL. 1987. The effects of changes in the environment on the spatial firing of hippocampal complex-spike cells. The Journal of Neuroscience 7: 1951-1968.

O'Keefe J. 1976. Place units in the hippocampus of the freely moving rat. Experimental Neurology 51: 78-109.

O'Keefe J, Burgess N. 1996. Geometric determinants of the place fields of hippocampal neurons. Nature 381: 425-8.

O'Keefe J, Recce ML. 1993. Phase relationship between hippocampal place units and the EEG theta rhythm. Hippocampus 3: 317-330.

Pastalkova E, Itskov V, Amarasingham A, Buzáki G. 2008. Internally generated cell assembly sequences in the rat hippocampus. Science 321: 1322-1327.

Ranck JB Jr. 1985. Head direction cells in the deep cell layer of dorsal presubiculum in freely moving rats. In G. Buzaki \& C. H. Vanderwolf (Eds.), Electrical activity of the archicortex. Budapest,Hungary: Akademiai Kiado. p. 217-220.

Restle F. 1957. Discrimination of cues in mazes: a resolution of the "place-vs- 
response" question. The Psychological Review 64: 217-228.

Skaggs WE, McNaughton BL. 1998. Spatial firing properties of hippocampal CA1 populations in an environment containing two visually identical regions. The Journal of Neuroscience 18: 8455-8466.

Smith DM, Mizumori SJ. 2006. Learning-related development of context-specific neuronal responses to places and events: the hippocampal role in context processing. The Journal of Neuroscience 26: 3154-3163.

Solstad T, Boccara CN, Kropff E, Moser MB, Moser El. 2008. Representation of geometric borders in the entorhinal cortex. Science 322: 1865-1868.

Taube JS, Muller RU, Ranck JBJr. 1990. Head-direction cells recorded from the postsubiculum in freely moving rats. I. Description and quantitative analysis. The Journal of Neuroscience 10: 420-435.

Tolman EC. 1948. Cognitive maps in rats and men. Psychological Review 55: 189208.

Watson JB. 1907. Kinaesthetic and organic sensations: their role in the reaction of the white rat to the maze. Psychological Review (Monograph Supplements) $8(2)$. 
Whishaw IQ, Cassel JC, Jarrard LE. 1995. Rats with fimbria-fornix lesions display a place response in a swimming pool: a dissociation between getting there and knowing where. The Journal of Neuroscience 15: 5779-5788.

Wood ER, Dudchenko PA, Robitsek RJ, Eichenbaum H. 2000. Hippocampal neurons encode information about different types of memory episodes occurring in the same location. Neuron 27: 623-633.

Zhang S-J, Ye J, Miao C, Tsao A, Cerniasukas I, Ledergerber D, Moser M-B, Moser El. 2013. Optogenetic dissection of entorhinal-hippocampal functional connectivity. Science, 340: 1232627. 
Figure legends

Figure 1 Example of place field repetition. In $1 \mathrm{~m} \times 1 \mathrm{~m}$ open box, a place cell fires primarily in one location. The rat was removed from the box, and a "haircomb" set of barriers was added. This was comprised five walls that created alleyways within the box. When the animals was returned to the environment, the place field exhibited fields within each of the alleyways created by the insert. In the raw data, black lines indicate the path taken by the animal, and red dots indicate the location of spikes. For the rate maps, warmer colours indicate higher rates of firing, and dark blue shading indicates areas visited by the rat, but where no firing was evident. Data courtesy of Roderick Grieves.

Figure 2 Example of place cell splitting. In this experiment, rats were trained to alternate continuously on a T-maze with return arms. Place cells on the central stem of the maze often showed high rates of firing when the animal was on travelling to one side of the maze, and little firing when running through the same location when travelling to the other side of the maze. Figure based on Wood et al., 2000. 


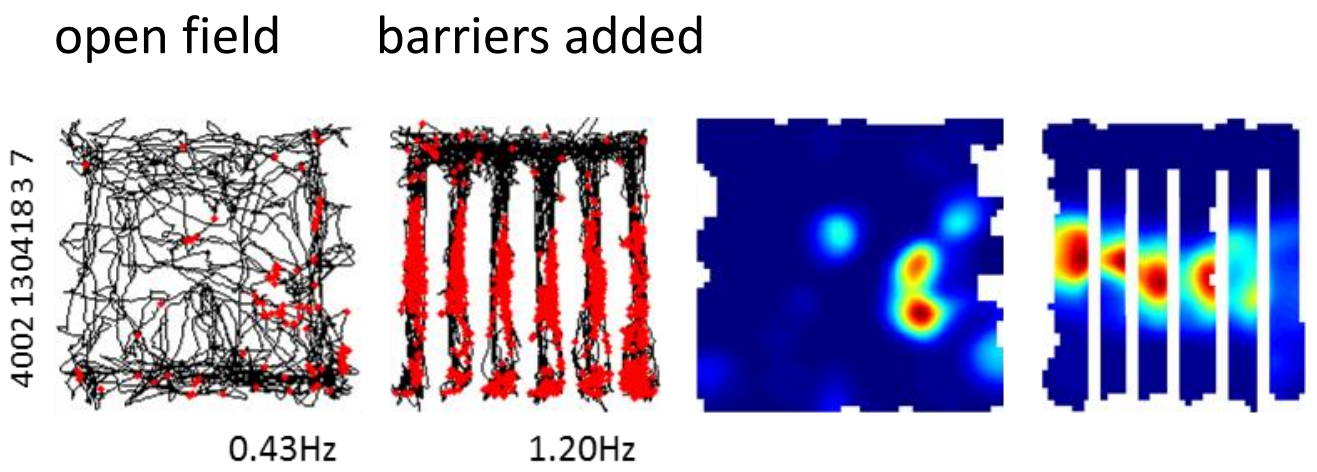

Figure 1 

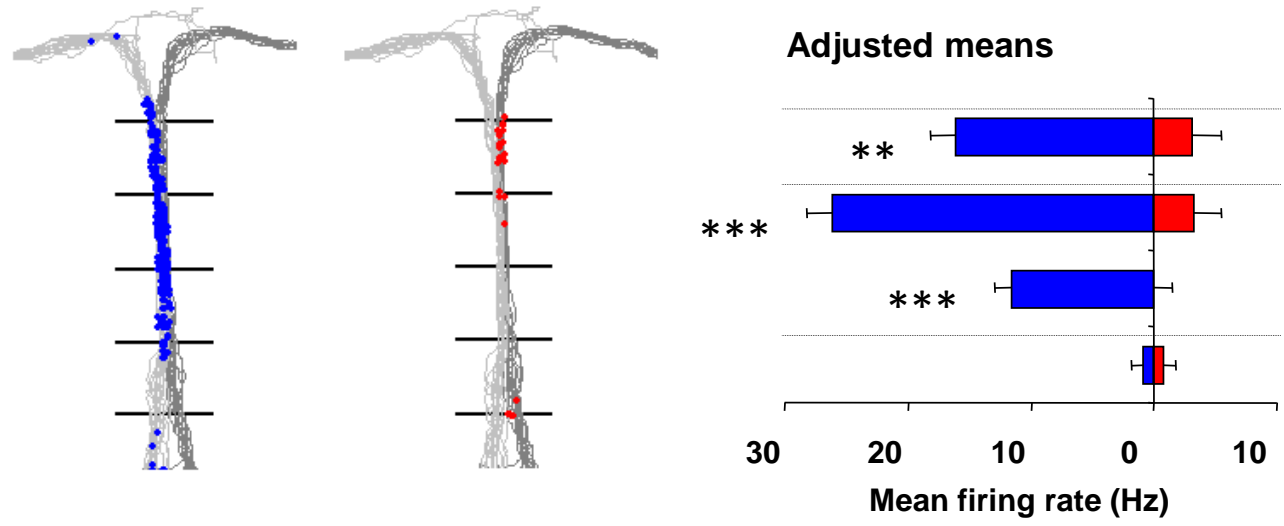

Figure 2 